\title{
Significados produzidos por professores e alunos envolvidos no programa Salas de Apoio à Aprendizagem no estado do Paraná ${ }^{1,2}$
}

Meanings produced by teachers and students involved on a learning support program in the state of Paraná

Significados producidos por profesores y alumnos involucrados en el programa Sala de Apoyo al Aprendizaje en la provincia de Paraná

\section{Francismara Neves de Oliveira, Carlos Toscano*}

Universidade Estadual de Londrina (UEL), Londrina, PR, Brasil

1 Agências financiadoras: CNPq e CAPES

2 O presente artigo foi publicado, em parte, no evento XII Congresso Internacional Galego-Português de Psicopedagogia, em 2013, e depois ampliado e reformulado.

FNO: doutora em Educação, e-mail: francis.uel@gmail.com CT: doutor em Educação, e-mail: ctoscano@uel.br 


\section{Resumo}

Este artigo analisa as significações de ensinar e de aprender produzidas por professores e alunos de salas de apoio à aprendizagem em duas escolas estaduais em Londrina (PR). De caráter qualitativo, adotando a modalidade descritiva-interpretativa, a pesquisa apoiou-se nos estudos de Ezpeleta e Rockwell (1986), Moysés e Collares (1992), Lahire (1997) e Aquino $(1997,1998)$, com o objetivo de compreender o trabalho desenvolvido nesses espaços de atuação. As perguntas de pesquisa foram: Quais as significações de alunos e professores a respeito do aprender e das dificuldades de aprender? Como a sala de apoio à aprendizagem é significada? Que significações estão presentes nos documentos norteadores do programa Salas de Apoio à Aprendizagem? Para sua realização, adotamos os seguintes procedimentos metodológicos: revisão bibliográfica, pesquisa documental, observação e entrevista. Dentre os resultados obtidos, destacamos: 1) a existência do programa Salas de Apoio à Aprendizagem sinaliza o reconhecimento do problema do não aprender como algo sistêmico; entretanto, suas ações são concentradas na oferta de salas de apoio somente para as disciplinas de Língua Portuguesa e Matemática, cujas aulas são, via de regra, percebidas pelos alunos como idênticas às que tiveram na sala regular e não compreenderam; 2) a busca de certa culpabilização dos sujeitos pelo não aprender é muito presente e, a depender do lugar ocupado nas relações, a culpa pode recair sobre o professor, sobre o aluno e/ou sobre sua família.

Palavras-chave: Educação. Cotidiano escolar. Ensinar e aprender. Significações de professores e alunos. Sala de apoio à aprendizagem.

\section{Abstract}

This work investigated the proposal of the state program of Paraná government for learning support rooms. Of qualitative character, on the modality of descriptive and interpretative, the research relied on studies of Rockweel and Speleta (1986); Moysés and Collares (1996); Lahire (1997); and Aquino (1997, 1998), with the goal of understanding the work developed on those performance spaces in two public schools of Londrina, $P R$, through the following questions: Which are the meanings of students and teachers about the teaching and the learning and about the support room? What are the meanings of the room to support learning? Which meanings are present on the guiding documents of the program? In order to achieve this goal, the following methodological 
procedures were adopted: documentary research, observation and interview. The results include: 1) the existence of this program signals the recognition of the problem of not learning is systemic, however, their actions are focused on providing a new opportunity for other classes only in Portuguese Language and Mathematics, perceived by students as they were identical to the regular room and not understand; 2) assigning blame for not learning is very dependent on the place occupied in context and so sometimes may involve the teacher or the student and/or his family.

Keywords: Education. School life. Teaching and learning. Learning support room. Teacher and students meaning.

\section{Resumen}

El trabajo analizó los significados del enseñar y aprender producidas por profesores y alumnos de la sala de apoyo al aprendizaje en dos escuelas provinciales situadas en Londrina-PR. De carácter cualitativo, en la modalidad de estudio descriptivo-interpretativo, la pesquisa se apoyó en los estudios de Rockweel y Speleta (1986); Moysés y Collares (1996); Lahire (1997); y Aquino (1997, 1998), con el objetivo de comprender el trabajo desarrollado en estos espacios de actuación. Como problema guía preguntamos: ¿Cuáles son los significados de alumnos y profesores a respecto del aprender y de las dificultades de aprender? ¿Cómo la sala de apoyo al aprendizaje se entiende? ¿Qué significados están presentes en los documentos orientadores del programa? Para su realización, adoptamos los siguientes procedimientos metodológicos: revisión bibliográfica, pesquisa documental, observación y entrevista. Entre los resultados obtenidos destacamos: 1) la existencia de que ese programa señala el reconocimiento del problema de no aprender como algo sistémico, mientras tanto, sus acciones son concentradas en la oferta de una nueva oportunidad de otras aulas solamente en Lengua Portuguesa y Matemáticas que son, en general, percibidas por los alumnos como idénticas a las que tuvieron en la sala regular y no las comprendieron; 2) la búsqueda de cierta culpabilidad por el no aprender entre los sujetos es muy presente y la de depender del lugar ocupado en las relaciones puede involucrar al profesor, al alumno y/o a su familia.

Palabras Clave: Educación. Cotidiano escolar. Enseñar y aprender. Significados de profesores y alumnos. Sala de apoyo al aprendizaje. 


\section{Introdução}

Ao pensarmos sobre a questão do aprender, é preciso reconhecer, em primeiro lugar, que, na complexidade da escola, os processos envolvidos são marcados por trajetórias diferenciadas, avaliadas como satisfatórias ou insatisfatórias. Nesse contexto, interatuam diferentes expectativas em relação ao domínio dos conteúdos escolares e à apreensão do conhecimento. Como lócus de expectativas tão diversas, é compreensível que a escola produza relações de inadequação, descontinuidade, rotulação e fragmentação, que coexistem com relações valorizadas como assertivas, pedagogicamente corretas, científicas.

No cenário escolar, encontramos um contexto de demandas e expectativas em torno daquele que aprende e, ao mesmo tempo, ansiedade e angústia proporcionadas pela ausência de compreensão acerca dos processos envolvidos no ensinar e no aprender.

A constatação de processos que não resultam na aprendizagem do aluno, na maioria dos casos, tem produzido estigmas e estereótipos que atingem a família, o aluno, o professor e a própria escola. O processo de aprendizagem engendra múltiplas possibilidades e seu sucesso ou insucesso depende de condições de construção ou reconstrução que não estão localizadas isoladamente nos sujeitos que participam do processo, nem no meio onde ocorre, nem mesmo nos objetos de estudo que possibilitam a apropriação do conhecimento acumulado histórica e culturalmente. Essa construção, e/ou reconstrução, é muito mais marcada pelo "e" que pelo "ou", o que denota a complexidade desse fenômeno.

No presente estudo, nossa discussão não recai sobre definições, nomenclaturas, classificações ou avaliações das usualmente denominadas "dificuldades de aprendizagem". Buscamos, no contexto de um programa de apoio à aprendizagem escolar, identificar as significações acerca do não aprender, produzidas por alunos e professores nas ações promovidas nesse cenário. Nesse sentido, interessa-nos revelar "o olhar" dos professores que atuam nesse espaço e "o olhar" dos alunos que frequentam esse mesmo espaço: a sala de apoio à aprendizagem. 


\section{Apontamentos teóricos}

A escola ocupa um lugar de destaque no projeto civilizatório. Nela, o que se ensina é considerado imprescindível ao processo de humanização na sociedade moderna. Ler, escrever, contar, interpretar, formular e resolver problemas, tendo por referência os conhecimentos sistematizados historicamente, não se constituem como processos naturais do desenvolvimento humano.

Nesses processos, interatuam prescrições e expectativas derivadas de políticas educacionais, expectativas do aprendiz em relação ao ambiente escolar, do professor quanto à conformidade do aluno aos objetivos da escola, de ambos quanto ao domínio de conteúdos escolares e à apreensão de conhecimentos que deverão ser demonstrados tanto em avaliações internas quanto externas, entre outros aspectos.

Abordar esse tema implica reconhecer a escola como espaço que remete a múltiplas questões a serem estudadas, tais como as significações atribuídas ao ensinar e ao aprender. Se, por um lado, essa reflexão tem mobilizado significativas pesquisas na área de educação e em áreas afins, por outro, ainda constitui, no cotidiano escolar, um desafio que se revela na compreensão superficial do problema e na consequente impossibilidade de ação para sua superação, propagando a impotência da escola, que se vê despreparada para lidar com as situações que se apresentam a ela.

Os modos de compreender e de lidar com o insucesso acadêmico dos alunos estão, na maioria dos casos, permeados por estigmas e estereótipos que, além de atingirem a eles e suas famílias, alcançam os professores e as escolas. Nessa perspectiva, ganha destaque o comportamento do aluno que é considerado, na maior parte dos casos, inadequado. (AQUINO, 1997).

Andrada (2003, p. 15), sobre essa questão, argumenta:

Qual o significado dos termos aluno com problema "ou" dificuldade de aprendizagem? São várias as possíveis respostas, várias as possíveis construções de significado acerca dos termos, sem que uma seja mais 
verdadeira que outra. Assim, não podemos previamente acreditar que alunos são problemas ou que famílias são desajustadas, ou que professores são autoritários. Precisamos ver um "quebra-cabeças", as partes e o todo!

É fato conhecido pelos que atuam na educação escolar que, no interior da escola, o não aprender tem sido frequentemente associado a uma figura muito polêmica: o "aluno-problema". Alerta-nos Aquino (1998, p. 2):

O aluno problema é tomado, em geral, como aquele que padece de certos supostos "distúrbios psico/pedagógicos"; distúrbios estes que podem ser de natureza cognitiva (os tais "distúrbios de aprendizagem") ou de natureza comportamental, e nessa última categoria enquadra-se um grande conjunto de ações que chamamos usualmente de "indisciplinadas". Dessa forma, a indisciplina e o baixo aproveitamento dos alunos seriam como duas faces de uma mesma moeda, representando os dois grandes males da escola contemporânea, geradores do fracasso escolar, e os dois principais obstáculos para o trabalho docente.

No cotidiano escolar, é comum nos depararmos com a perplexidade dos professores diante das denominadas "dificuldades de aprendizagem". Observamos ainda um crescimento do volume de alunos encaminhados anualmente aos serviços de apoio pedagógico, contraturno, serviços psicopedagógicos, fonoaudiológicos e psicológicos, além dos encaminhamentos feitos anualmente pelas escolas aos profissionais da área médica (MOYSÉS; COLLARES, 1992).

Vale ressaltar que não se trata necessariamente de uma crítica aos serviços citados, mas da constatação de que o professor muitas vezes é levado a selecionar e encaminhar os alunos cujo rendimento escolar é insatisfatório a outros profissionais, para que façam o que ele considera fora de seu alcance, ou porque não visualiza as condições para as ações que considera necessárias. Esse processo favorece a desconsideração da dimensão pedagógica nos encaminhamentos dados e nos modos de lidar com o não aprender na escola.

Essa aparente impotência do professor remete a múltiplos fatores próprios à complexidade de um processo que envolve sua formação e, 
portanto, o arcabouço teórico sobre o qual suas concepções e sua prática se materializam, as condições efetivas do trabalho docente e a política educacional que impõe direções que alcançam a organização da escola e do trabalho pedagógico.

Partindo de premissas equivocadas ou insuficientes, de diagnósticos aligeirados, a identificação de "dificuldades de aprendizagem" e, consequentemente, os encaminhamentos dados perdem eficácia tanto para sua prevenção quanto para sua reparação por parte da escola. Como parte do mesmo processo, a culpabilização e a vitimização do professor são também produzidas, mas veladas pela apropriação de um discurso que se justifica pelo não saber como lidar com as práticas reprodutoras de segregação daqueles que não correspondem às expectativas e idealizações da escola (COLLARES; MOYSÉS, 1986; GOFFMAN, 1988).

As características e os padrões definidores da normalidade no processo de ensino-aprendizagem, e a consequente patologização daqueles que não se adequam a eles, encontram-se, em certa medida, ancorados na literatura científica. Na prática, o problema continua percebido de forma pontual e localizado no aluno, reafirmando estigmas e preconceitos (LUGLI; GUALTIERI, 2012; PATTO, 1999; SOUZA, 2008).

Contrapondo-se a essa perspectiva, no cotidiano escolar, podem ser percebidas, em relações de interdependência, condições do aluno e do professor, relações de trabalho, fatores escolares e fatores extraescolares que configuram certo contexto favorável e/ou desfavorável ao ensinar e ao aprender (BRITO, 2009; EMÍLIO, 2004; EZPELETA; ROCKWELL, 1986; LUZ et al., 2011; MERCADO-MALDONADO, 2002; PANIAGO, 2005).

Lahire (1997) também problematiza a figura do aluno-problema ao considerar que as ações e reações de um aluno nada significam fora das relações sociais em que são tecidas - ainda que no interior de seu grupo familiar, ou de pessoas próximas que lidam com ele, haja um universo de objetos ligados a tais relações sociais. Nesse sentido, o autor considera que o aluno localizado socialmente no ambiente escolar não reproduz, necessariamente e de maneira direta, as formas de agir de sua família. Suas ações são, antes, reações que se apoiam, de forma relacionada, nas 
ações dos adultos com os quais ele tem contato e que, sem sabê-lo, "desenham, traçam espaços de comportamentos e de representações possíveis para ele" (LAHIRE, 1997, p. 17). Portanto, os processos que envolvem o ensinar e o aprender, bem como as significações que nele se produzem, ligam-se aos sentidos oriundos de outros contextos e interações.

Reconhecer os elementos contextualmente articulados oferece outras possibilidades de atribuir significado ao não aprender na escola. Ao reconhecer que o ensinar e o aprender constituem um processo dinâmico, complexo e de muitas faces, Fagali (2001, p. 22) nos propõe várias questões para reflexão:

[...] o que é aprender, olhando a existência das pessoas, suas necessidades de troca e socialização, as questões éticas de respeito humano e os valores frente às novas perspectivas do existir? O que é aprender, diante da diversidade cada vez maior de informações que se impõem com aceleração crescente, na louca corrida, frente aos desafios de sobrevivência? E o personagem do professor? Que lugar é este que ele ocupa e quais as possibilidades de ocupar outros lugares? [...] Em vista dessas possibilidades de transformação, quais são as qualidades das experiências educacionais que devem permanecer e que poderão fazer sentido para as necessidades humanas? O que deve ser alterado e aperfeiçoado, por não responder mais às nossas necessidades em transformação, neste momento histórico, na nossa cultura?

Ao analisar diferentes configurações sociais e relacioná-las com resultados obtidos em exames realizados por estudantes originados de meios populares, Lahire (1997, p. 18) considera que "as condições de existência de um indivíduo são primeiro e antes de tudo as condições de coexistência" e, somente compreendendo isso, podemos evitar "todas as formas de reificações destas condições de existência em forma de propriedades, de capitais, de recursos abstraídos (das relações sociais efetivas)".

De acordo com esse autor,

[...] temos a tendência a reificar os comportamentos das crianças em traços de caráter ou de personalidade, [...] [mas esses] não aparecem 
em um vazio de relações sociais: são, sim, o produto de uma socialização passada, e também da forma das relações sociais através das quais esses traços se atualizam, são mobilizados (LAHIRE, 1997, p. 17).

Tal compreensão convida-nos a pensar acerca da constituição do sujeito nas inter-relações próprias do ensinar e aprender. Assim, o aprender é concebido como um processo, e não como um estado (resultado ou produto), e a escola como uma importante instituição (não apenas física, mas de interações) para a elaboração do conhecimento.

Diante do exposto, no presente estudo focalizamos os significados produzidos por alunos e professores acerca do não aprender no contexto específico de um programa de apoio à aprendizagem escolar. Em um primeiro momento, buscamos identificar as significações inferidas dos documentos normativos constituintes das diretrizes norteadoras do programa de apoio à aprendizagem e que definem sua política e seus agentes. Posteriormente, interessou-nos compreender o cotidiano de trabalho desenvolvido nesse contexto e as significações produzidas pelos participantes.

\section{Caracterização do estudo}

O presente estudo envolveu, inicialmente, a análise da legislação que define o programa Salas de Apoio à Aprendizagem na rede estadual de ensino do Paraná e instaura vários procedimentos no cotidiano escolar. Num segundo momento, com relação ao estudo de campo, orientamo-nos pelos parâmetros da pesquisa qualitativa, na modalidade de estudo descritivo-interpretativo (GIL, 2002). Para tanto, a pesquisa contemplou a observação do cotidiano de salas de apoio de duas escolas estaduais em Londrina (PR), durante dois meses, com oito horas semanais, sendo quatro horas em cada escola, ocasiões em que também foram realizadas entrevistas com os professores e alunos. Para a coleta dos dados, elaboramos um diário de campo para o registro de nossas observações e fizemos uso de gravador no momento das entrevistas. 


\section{Resultados e discussão}

Apresentamos e discutimos os dados de nosso estudo organizados em três eixos de análise: da caracterização geral do programa de apoio à aprendizagem, de questões relacionadas ao funcionamento do programa e, por fim, das significações produzidas por professores e alunos acerca do não aprender e da sala de apoio.

\section{Caracterização geral do programa de apoio à aprendizagem}

O programa Salas de Apoio à Aprendizagem (SAA) faz parte das políticas educacionais do Governo do Estado do Paraná e está em vigor desde 2008. O referido programa busca desenvolver ações para o enfrentamento de problemas relacionados à aprendizagem dos alunos, nos conteúdos básicos das disciplinas de Língua Portuguesa (oralidade, leitura, escrita) e de Matemática (formas espaciais, operações básicas e elementares) (PARANÁ, 2011c, 2012).

Conforme a Resolução n. 1690 (PARANÁ, 2011a), a SAA está inserida no Programa de Atividades Complementares Curriculares em Contraturno na Educação Básica, que foi instituído a partir do ano de 2011 em caráter permanente na Rede Estadual de Ensino.

Seu funcionamento ocorre no turno contrário ao da matrícula do aluno e sua abertura é automática para os alunos matriculados no $6^{\circ}$ ano e no $9^{\circ}$ ano do Ensino Fundamental. Poderá ser solicitada autorização para o atendimento de alunos do $7^{\circ}$ ano e do $8^{\circ}$ ano, desde que haja justificativa fundamentada da escola, acompanhada do parecer do Núcleo Regional de Educação e análise pelo Departamento de Educação Básica (DEB)/Coordenação de Educação Integral (PARANÁ, 2011,2012).

As salas de apoio, de acordo com a Instrução n. 007/2011 (PARANÁ, 2011b), são organizadas em turmas de, no máximo, 20 alunos, e seu funcionamento é condicionado à disponibilidade de espaço físico 
adequado, à frequência dos alunos, à existência de professor e a um Plano de Trabalho Docente integrado ao Projeto Político-Pedagógico da escola.

O processo de diagnóstico e encaminhamento dos alunos que não estão acompanhando a aprendizagem de forma satisfatória deve ser realizado pelo professor da sala regular. Após o diagnóstico, cabe ao professor da sala regular preencher uma ficha de encaminhamento ${ }^{3}$ referente à disciplina e indicar, em conjunto com o pedagogo, a composição das turmas.

De acordo com a Instrução n. 007/2011 (PARANÁ, 2011b), cabe ao pedagogo orientar as famílias a respeito do programa, informando sobre a importância da participação do aluno. A instrução prevê, ainda, que os professores da SAA desenvolvam um Plano de Trabalho Docente adequado à superação das dificuldades apresentadas pelos alunos, além de serem responsáveis pelo registro de sua frequência e participação. Todos os profissionais responsáveis pelo funcionamento da sala de apoio à aprendizagem (professor da sala regular, professor da sala de apoio e pedagogo) deverão realizar o registro dos resultados do trabalho desenvolvido nesse espaço num relatório semestral a ser encaminhado ao Núcleo Regional de Educação.

\section{Aspectos que impactam no funcionamento do programa SAA}

Um programa que se propõe a atender a questões relativas ao insucesso escolar pressupõe um conjunto de iniciativas que precisam estar articuladas de modo a oportunizar ações de vários âmbitos em favor da aprendizagem escolar. Tais ações têm início na legislação que instaura o programa nas unidades escolares e se desdobra nos delineamentos que materializam o fazer pedagógico em realidades específicas nos diferentes contextos das SAA. Nesse sentido, tomando como referência a legislação

3 A ficha de encaminhamento e avaliação dos alunos pode ser acessada no portal Dia a dia Educação, do governo do Paraná, em: <http://www.gestaoescolar.diaadia.pr.gov.br/arquivos/ File/pdf/ficha_lingua_portuguesa.pdf> e <http://www.gestaoescolar.diaadia.pr.gov.br/arquivos/ File/pdf/ficha_matematica.pdf >. 
que normatiza o referido programa (Resolução n. 1690), passaremos a analisar os aspectos que interferem em seu contexto e que, em conjunto, caracterizam o processo de atendimento. Destacaremos os seguintes aspectos: responsabilização pelo não aprender, atribuição de tarefas, critério definidor do tempo de permanência dos alunos no programa, limitação de opções de áreas de conhecimento a serem trabalhadas; avaliação dos alunos pelos professores das salas regulares e da sala de apoio, tanto no que concerne ao seu encaminhamento quanto à sua saída do programa.

As diretrizes do programa Salas de Apoio à Aprendizagem, projeto único em toda a rede estadual, pressupõem que a responsabilidade pelo não aprender (comprovada pelas estatísticas de reprovação e de evasão no Ensino Fundamental) pertence às escolas e, por conseguinte, aos professores; entretanto, a preocupação com as teorias sustentadoras do trabalho docente é uma dimensão ausente no referido programa, assim como outras questões relacionadas às condições em que esse trabalho é realizado.

Quanto ao tempo de permanência do aluno na SAA, destacamos a ausência de delimitação de um prazo mínimo, o que, nas escolas investigadas, assumiu um lugar restrito à organização do funcionamento da SAA, em detrimento do processo de ensino-aprendizagem ali desenvolvido. Constatamos que, por vezes, há alunos permanecendo no programa por tempo inferior a um bimestre letivo. Tal procedimento foi justificado pela necessidade de ampliar o número de alunos atendidos pelo programa durante o ano e também esteve relacionado à limitação de vagas ofertadas em cada turma. Esse procedimento, em nosso entender, poderia tornar superficial o trabalho desenvolvido, por não propiciar tempo necessário para o desenvolvimento de um trabalho mais completo, que leve à recuperação da defasagem na aprendizagem do aluno, a qual o programa se propõe a realizar.

Além dos fatores já indicados, verificamos que as atribuições dos envolvidos nesse trabalho estão voltadas muito mais ao âmbito administrativo que ao âmbito pedagógico, centram-se no preenchimento de fichas avaliativas dirigidas a diferentes membros e instâncias do sistema educacional. Tal predomínio do administrativo sobre o pedagógico também se evidencia na ausência de formação continuada: apesar de 
previstos nos documentos oficiais, inexistem concursos específicos para selecionar quem atuará na sala de apoio ou encontros frequentes que busquem promover, conjuntamente, uma reflexão sobre o funcionamento do programa e dos resultados obtidos. Nesse contexto, não é incomum e, por vezes, oportuno atribuir ao professor e à metodologia empregada, ou ao aluno e a sua família (considerada não envolvida), a responsabilidade pelo fracasso do processo de aprender.

Com relação às disciplinas eleitas como objeto de trabalho, o programa repete, a exemplo do que ocorre no ensino regular, a supervalorização das áreas de Língua Portuguesa e Matemática, desconsiderando as demais áreas de conhecimento do currículo. Em consequência disso, o âmbito do trabalho docente a ser realizado é restringido. Além disso, por vezes, observamos repetição de conteúdos e metodologias empregados na sala regular. A dinâmica da aula se apresentava da mesma forma; por exemplo, era solicitada a leitura de textos em que cada aluno lia um trecho em voz alta, geralmente de forma sofrível, o que impedia sua compreensão. Pelas características do grupo de alunos, a leitura era frequentemente interrompida, realizada de forma muito lenta, com interferências constantes do professor, e essa prática ocupava praticamente todo o tempo da aula de Língua Portuguesa. Observamos ainda que a cópia das respostas dos exercícios do livro, registradas pelo professor no quadro, nem sempre significava a compreensão do assunto. Questões interpretativas e problemas matemáticos eram ditados aos alunos para que os respondessem em seus cadernos, sem que se verificasse se a compreensão do tema tratado havia sido atingida. O tempo dedicado a leitura, cópia e ditado ocupava o lugar da discussão, da interpretação e, portanto, da compreensão.

Com relação aos encaminhamentos dos alunos para a sala de apoio, verificamos semelhanças quanto ao modo como foram realizados nas duas unidades escolares investigadas. Nas primeiras semanas do ano letivo as salas de apoio à aprendizagem foram constituídas, partindo-se das indicações dos professores das salas regulares de $6^{\circ}$ ano ( $5^{\mathrm{a}}$ série). O número máximo de vagas determinado na legislação (20 alunos por sala) foi dividido pelo número de salas de $6^{\circ}$ ano na escola. 
Constatamos, no universo observado, que nem mesmo o critério para a seleção de alunos, centrado nas notas baixas, foi empregado na escolha do grupo que passou a frequentar a sala de apoio no primeiro bimestre letivo. Na terceira semana de aula, os alunos já haviam sido encaminhados - portanto, antes das avaliações regulares do bimestre. Nas entrevistas com os professores, pudemos verificar que os critérios utilizados para o encaminhamento dos alunos envolviam: feeling do professor, empatia ou não com o aluno, observação de seu comportamento nos primeiros dias de aula (indisciplina), informações sobre sua família e ocorrências em anos anteriores.

De acordo com os dados obtidos, o aluno passou a frequentar a sala de apoio em função de sua inadequação a um modelo idealizado. Foi encaminhado como um "aluno-problema", pois reunia em si as impossibilidades de aprender. Nesse contexto, assim que o aluno cumpria sua passagem pela sala de apoio, podia retornar à "normalidade" da sala regular. Alguns alunos frequentaram apenas por duas semanas a sala de apoio e foram autorizados a sair do programa. Exemplificamos com uma situação observada em uma das unidades escolares, em que um aluno foi incluído na sala de apoio na penúltima semana do primeiro semestre letivo porque vinha apresentando indisciplina em sala.

A avaliação das atividades realizadas indicou que os responsáveis das escolas, ao receberem a visita da equipe avaliadora, relataram o andamento do trabalho, porém receberam, muitas vezes, o retorno da avaliação quando o ano já havia terminado, sem que os alunos fossem assistidos ao longo do período e sem que os professores (da sala regular e da sala de apoio) fossem orientados em um processo de acompanhamento aos escolares.

Conforme alerta-nos Paro (2001, p. 41-42):

Para os reprovados, o absurdo da situação não é apenas que se espera todo um ano para se verificar que o processo não deu certo (o que já não é de pouca gravidade); o absurdo consiste também em que nada se faz para identificar e corrigir o que andou errado. Não se trata propriamente de uma avaliação, mas de uma condenação do aluno, como se só 
ele fosse culpado pelo fracasso. Como se o processo não fizesse parte do aluno, o professor (ou professores) e todas as condições em que se dá o ensino na escola.

A apresentação de algumas questões relativas ao funcionamento da sala de apoio nos permite afirmar que há um distanciamento entre o previsto na legislação normatizadora, ou entre o que foi pensado para ela, e as condições objetivas de realização do trabalho no cotidiano da escola. As ações observadas nesse espaço são tecidas nas relações integradoras de várias interlocuções e articulam múltiplos interesses, o que permite, nesse contexto, a produção de significados diversos ao não aprender, o que discutiremos a seguir.

\section{Significações produzidas por professores e alunos acerca do não aprender e da sala de apoio}

Nas entrevistas que fizemos com os professores (identificados por Prof. 1, 2, 3 e 4), buscamos investigar como significavam os problemas relativos à aprendizagem de seus alunos, por meio de questões que envolviam: o que entendem por aprender e não aprender, quais as principais características dos alunos que frequentam a sala de apoio e que fatores atribuíam ao não aprender.

Com relação ao que os professores entendem por aprender, destacamos a resposta do Prof. 1:

Aprender é uma reação de interesse, reação a tudo que desperta interesse de qualquer cidadão, e até de uma criança. Ele aprende desde que esteja interessado. Já o não aprender, ou seja, as dificuldades de aprendizagem, eu vejo assim: podem ser problemas extraclasse que afetam muito a capacidade de aprendizagem - o estilo de vida que ele tem, os problemas familiares, dificuldades financeiras, enfim, diversas situações que afetam o aprendizado. O aprendizado em si é uma absorção de conhecimentos, daquilo que é importante para ele. O aprendizado vai muito em cima daquilo que ele vive. 
Percebe-se nessa fala a indicação de que o não aprender é produzido por fatores que estão exclusivamente fora da escola, ou localizados no sujeito e/ou em sua família, enquanto a escola é desconsiderada como coprodutora do fenômeno. Esse pensamento acerca do não aprender, conforme Bissoto (2009), é possível porque a aprendizagem é percebida como dissociada do conhecimento e da relevância do processo de conhecer para a humanização do sujeito. De acordo com esse autor:

O conhecimento tem, para a espécie humana, valor vital, é essencial para a adaptabilidade dos indivíduos ao entorno. Dessa forma, para aprender, é preciso que aquele que aprende aceite o conhecimento como algo importante para a sua ontogenia, para seus esforços de se pôr-no-mundo. [...]O ser humano se humaniza enquanto se socializa, ou seja, enquanto é introduzido e vai se tornando parte da rede de significados, que sustenta a vida de uma coletividade. Significados que formam um fundo de conhecimentos sócio-historicamente constituídos, e sem o qual a espécie humana não teria reunido condições de evolução. A constituição e a manutenção de relações interpares, cultural e historicamente situadas, são fundamentais para o desenvolvimento integral do sujeito, e não podem ser relegadas pela escola (BISSOTO, 2009, p. 93-94).

Sobre as características do aluno que frequenta a sala de apoio à aprendizagem, destacamos três respostas:

Prof. 1: É sempre aquele aluno que tem dificuldades extrassala: problema familiar, falta de acompanhamento dos pais, desinteresse dos pais de acompanhar a vida escolar dos filhos. Então acho que isso dificulta bastante.

Prof. 2: São alunos que têm dificuldades pra se concentrar, são muito agitados, e o principal é a interpretação, pois muitos vão bem nas regras da gramática, conseguem decorar, mas, quando chegam à interpretação, não conseguem abstrair.

Prof. 3: Ou ele é muito tímido, ou impulsivo, ou agressivo, ou disperso. 
Quanto às causas do não aprender, os professores assim se manifestaram:

Prof. 1: A causa principal é isso... eu sempre relaciono muito a família como aluno. Então, se ele tem uma família que o acompanha, que está sempre atenta, participa da vida escolar dele, isso o ajuda a eliminar essas dificuldades.

Prof. 3: É o aluno [não] conseguir se concentrar, ele [não] querer. Porque atualmente o que compete com a escola são coisas que não conseguimos alcançar, por exemplo, o vídeo, a internet, televisão, é tudo, então a competição está muito desleal. Ele tem acesso a muitas coisas que dão mais prazer que a escola, onde ele tem que parar para se concentrar, e é tudo muito rápido, a internet dá respostas rápidas e prontas, ele não precisa raciocinar muito, não. Agora, na escola, ele tem que parar, se concentrar e pensar, e aí a preguiça mental impera.

Embora haja reconhecimento de variados elementos compondo o processo de aprendizagem, constatamos que ainda predomina o entendimento de que o não aprender é responsabilidade do aluno e que um conjunto de atributos (negativos) imputados a ele parecem assumir um caráter permanente, e isso o impediria de agir, de pensar, de aprender.

Esse modo de compreender, entretanto, não foi o único que surgiu em nossa pesquisa. O Prof. 4 apresentou o entendimento de que não desconsiderava a integração entre escola, aluno e família:

A aprendizagem é processo. De nada adianta eu acelerar os conteúdos, se o raciocínio não acompanha. Não dá pra ignorar, na aprendizagem, outras dimensões relativas à história de vida deles. Veja, aqui [mostra os alunos] são diferentes histórias, marcas que interferem. O processo de cada um vai ser diferente. A gente [se] pergunta mais [a respeito de] $o$ que eles não sabem e pouco o que a gente pode fazer por eles como escola. Se não aprendem, não é só porque têm uma vida difícil. A escola também não atinge a necessidade de aprendizagem deles... é tudo junto, escola, aluno, família. 
Nessa fala, observamos outro olhar dirigido aos sujeitos, pois julga-os portadores de uma história que não é somente deles. Há a consideração de que nos constituímos como sujeitos sociais e culturais que se apresentam no interior da escola nos processos interativos entre os sujeitos que dela participam, o que nos remete à observação de Roustang (1990 apud LAHIRE, 1997, p. 18): "cada traço que atribuímos ao indivíduo não é seu, mas corresponde mais ao que acontece entre ele e alguma outra coisa (ou alguma outra pessoa)".

Quanto à significação acerca do papel da sala de apoio, os professores participantes foram unânimes em ressaltar seu valor positivo, mas como uma nova oportunidade oferecida aos alunos. Para exemplificar, destacamos a fala de um de nossos sujeitos, o Prof. 3 :

Digo aos alunos e aos seus familiares que o Estado está pagando professor particular para eles e que, se não valorizarem, nada mais poderá ser feito. Depende deles [dos alunos e família] superarem ou não as dificuldades que têm. Essa oportunidade que o governo está dando é algo muito importante, porque as famílias deles nunca conseguiriam pagar por esse serviço.

Observa-se, ainda que de outra forma, a reafirmação do entendimento de que o aprender seria responsabilidade apenas do aluno e de sua família. Em consequência, deles se esperaria a busca de solução para o seu não aprender.

No que se refere às significações do não aprender entre os alunos, investigamos se gostam da sala de apoio, as semelhanças e diferenças entre as atividades escolares da sala regular e as da sala de apoio, por que acham que foram escolhidos para a sala de apoio, que tipo de aluno eles pensam ser e o que a professora, a família e os amigos acham de eles participarem da sala de apoio.

As respostas apresentadas pelos alunos indicam que eles estariam incorporando o discurso que os culpabiliza. Em nosso entendimento, o insucesso na escola é materializado na tessitura resultante das interações dos sujeitos que constituem o cotidiano escolar, lócus de produção de sentidos acerca de si mesmo, do outro, dos processos de aprender, das 
demandas postas e das capacidades percebidas para atendê-las. Dos 25 alunos entrevistados nas duas salas de apoio (doravante identificados como Al. 1, Al. 2, Al. 3, ..., Al. 25), a maioria considera-se indisciplinada (malcomportada) e, por essa razão, mereceria estar na sala de apoio. Embora afirmem que a sala de apoio é um lugar privilegiado para aprender, evidenciam muitas semelhanças e poucas diferenças entre a sala de apoio e a sala regular, o que estaria de acordo com o observado: repetições de conteúdo, de propostas e de metodologia nos dois espaços. Algumas respostas apresentadas:

Al. 3: O que ensinam é igual, uma chatice porque repete a aula.

Al. 6: As carteiras, o ensino, usam o livro, a bagunça.

Al. 13: Copiar do quadro, o jeito do ensino.

Al. 21: As bagunças, as matérias.

Al. 17: As atividades, a leitura.

Quando perguntamos por que foram escolhidos para a sala de apoio, enfatizaram o quanto eram maus alunos, o quanto viam-se incapazes de aprender. Seguem algumas das respostas:

Al. 2: Eu sou muito fraco e aqui eles ajudam a recuperar.

Al. 11: Moro com minhas tias, avós e mãe, acho que elas não incentivam.

Al. 25: Na hora [refere-se ao momento em que foi comunicada que iria para a sala de apoio] eu não senti nada, eu sabia que precisava vir e, mesmo que eu fosse boa aluna, seria escolhida pra cá. A professora pegava no meu pé e eu era ruim mesmo.

As falas que destacamos são reveladoras de quanto o processo de culpabilização já atingiu a esses alunos, fazendo com que incorporem o discurso de que têm um problema em si, ou em suas famílias. O modo como esses alunos indicam perceber sua participação na escola e na sala de apoio chama atenção para o fato de que as vivências no contexto escolar são fundamentais para a internalização de formas culturais de comportamento consideradas adequadas ou inadequadas à demanda escolar. Isso confere ao sujeito sentido de pertencimento ou de alienação e abandono 
do próprio processo de escolarização. Com relação ao sentido de pertencimento do aluno à escola, Bissoto (2009, p. 83, grifos do original) analisa:

Quanto maior o sentimento de pertencer, de fato, à instituição escolar, menos alienado o estudante estará desse processo. A alienação do processo educacional é entendida aqui como a atitude de distanciamento ou de estranhamento que o estudante desenvolve em relação aos processos de aprendizagem acadêmica ou aos processos de socialização, que transcorrem na instituição escolar. Essa atitude interfere decisivamente na atribuição e significados que o estudante faz quanto aos conhecimentos escolares e aos modos de serem valorizados pela escola; $e$ está, assim, na base da (não) apropriação que ele fará desses conhecimentos e comportamentos. Esse processo de estranhamento está na base da emersão do fenômeno do fracasso escolar.

Investigando o que pensam seus amigos, a professora e suas famílias sobre sua aprendizagem, a percepção dos alunos não difere do que analisamos até agora:

Al. 20: Minha professora acha que sou bagunceira, namoradeira.

Al. 4: Meus amigos tiram sarro, me chamam de burra.

Al. 8: Meus amigos acham que sou trouxa.

Al. 16: Minha mãe acha que eu tenho que vir mesmo, pra ficar mais inteligente.

Al. 1: Minha família acha que eu sou ruim.

Al. 12: Eles [família] não gostam. Acham ruim eu estar no reforço já no começo do ano.

Al. 24: Ela [professora] não acha nada porque só grita e não conversa com os alunos.

Observamos, mediante os dados obtidos, a força dos estereótipos e como permeiam todos os espaços, desde as políticas de implantação até o modo como crianças e seus familiares se veem participantes desse processo, o que, em nosso entender, inviabiliza os objetivos para os quais um espaço de apoio à aprendizagem é instituído.

Nesse sentido, os dados do estudo recolocam a discussão dos determinantes do não aprender, partindo dos efeitos provocados pela 
dinâmica dos acontecimentos que acabam conferindo total responsabilidade às pretensas inabilidades do sujeito que aprende. O que observamos nos dizeres dos alunos entrevistados resulta de um processo pelo qual crenças foram naturalizadas de forma tão poderosa que é o próprio sujeito que as verbaliza, ora assumindo-se como responsável pelos resultados obtidos, ora atribuindo às suas condições socioeconômicas e aos seus familiares as razões para o não aprender.

Esse mesmo processo alcança, concomitantemente, o professor, que passa a ser considerado despreparado, incompetente, desgastado emocionalmente, entre outros estigmas a ele atribuídos. Em suma, esse processo não é compreendido como multicausal, dotado de várias faces, inserido nas interações escolares, nas histórias de vida dos sujeitos e nas relações institucionais; diante de tal incompreensão, ficam (todos) impedidos de assumir o fracasso escolar de forma corresponsável.

\section{Considerações finais}

A análise dos dados deste estudo apontou para desencontros entre os caminhos trilhados pelo aluno na construção do conhecimento e o que significa aprendizagem nas propostas governamentais, bem como para a escola e para o professor.

A relação existente entre os documentos normativos, o desenvolvimento do trabalho e as significações de alunos e professores acerca do não aprender nas salas de apoio permite perceber a presença constante de uma tentativa de culpabilização que permeia todo o processo de aprendizagem, marcado por um resultado oposto ao seu objetivo. Esse contexto em que a rotulação e a segregação encontram lugar acaba inviabilizando a valorização de um processo em permanente (re)construção.

O funcionamento das salas de apoio à aprendizagem, revelado por este estudo, aponta, por um lado, o reconhecimento de um problema sistêmico a que a proposição e implantação do programa procuram, de alguma forma, responder. Por outro lado, aponta que as questões 
envolvidas nos problemas relativos às aprendizagens escolares são analisadas de forma dicotômica e desarticuladas, de modo que o processo corre o risco de resumir-se a um "ritual de passagem".

O não aprender é um problema que requer tratamento por parte de políticas educacionais, e o primeiro fator a ser levado em conta são as próprias condições de produção da educação escolar em nossa realidade. Uma vez produzido o insucesso escolar, faz-se necessário levar em conta os elementos elucidadores da rede de relações de interdependência entre os fatores que o geram.

Nessa perspectiva, um programa que tenha como objetivo contribuir decisivamente para a alteração de um quadro de insucesso escolar não pode prescindir de ações que levem em conta não só o fato de o aluno não aprender, mas também seu contexto imediato (fatores intraescolares) e mediato (fatores extraescolares), que alcança a família do aluno e o seu grupo social mais próximo. Faz-se ainda necessário romper com o círculo vicioso da culpabilização e da vitimização. Esse rompimento requer reflexão por parte de professores e gestores educacionais, de modo que conhecimentos possam ser produzidos a partir do contato com novos campos teórico-metodológicos que possibilitem a superação dos modos de lidar com o insucesso escolar, comumente reiterados no cotidiano escolar. Para isso, a gestão das políticas públicas educacionais deve assumir responsabilidades para com a formação continuada do profissional que atua na educação escolar e, em especial, no contexto analisado, além de acompanhar efetivamente o processo desenvolvido no programa de apoio à aprendizagem.

\section{Referências}

ANDRADA, E. G. C. Família, escola e a dificuldade de aprendizagem: intervindo sistemicamente. Psicologia Escolar e Educacional, v. 7, n. 2, p. 171-178, dez. 2003. AQUINO, J. G. Erro e fracasso na escola: alternativas teóricas e práticas. 2. ed. São Paulo: Summus, 1997. 
AQUINO, J. G. A indisciplina e a escola atual. Revista da Faculdade de Educação, v. 24, n. 2, p. 181-204, jul./dez. 1998.

BISSOTO, M. L. O fracasso na escola. Revista Iberoamericana de Educación, n. 50, p. 81-98, 2009.

BRITO, A. Acerca de um desencuentro: la mirada de los professores sobre los alumnos de la escuela secundaria em Argentina. Revista Iberoamericana de Educación, n. 51, p. 139-158, 2009.

COLLARES, C. A. L.; MOYSÉS, M. A. A. Preconceito no cotidiano escolar: ensino e medicalização. São Paulo: Cortez, 1986.

EMÍLIO, S. A. O cotidiano escolar pelo avesso: sobre laços, amarras e nós no processo de inclusão. 2004. $252 \mathrm{f}$. Tese (Doutorado em Psicologia) - Instituto de Psicologia, Universidade de São Paulo, São Paulo, 2004.

EZPELETA, J.; ROCKWELL, E. Pesquisa participante. São Paulo: Autores Associados, 1986.

FAGALI, E. Q. Múltiplas faces do aprender: novos paradigmas da pós-modernidade. São Paulo: Unidas, 2001.

GIL, A. C. Métodos e técnicas de pesquisa social. São Paulo: Atlas, 2002.

GOFFMAN, I. Estigma: notas sobre a manipulação da identidade deteriorada. 4. ed. Rio de Janeiro: Guanabara, 1988.

LAHIRE, B. Sucesso escolar nos meios populares: as razões do improvável. São Paulo: Ática, 1997.

LUGLI, G. R.; GUALTIERI, E. C. R. A escola e o fracasso escolar. São Paulo: Cortez, 2012.

MERCADO-MALDONADO, R. Los saberes docentes como construcción social. México: Fondo de Cultura Económica, 2002. 
LUZ, S. P. da et al. Formação continuada de docentes do ensino superior: contribuições para a prática pedagógica. Educere et Educare: Revista de Educação, v. 6, n. 12, p. 194-207, jul/dez. 2011.

MOYSÉS, M. A. A.; COLLARES, C. A. L. A história não contada dos distúrbios de aprendizagem. Cadernos CEDES, n. 28, p. 31-48, 1992.

PANIAGO, M. L F. S. Práticas discursivas de subjetivação no contexto escolar. 2005. 205 f. Tese (Doutorado em Linguística) - Universidade Estadual Paulista, Araraquara, 2005.

PATTO, M. H. S. A produção do fracasso escolar: histórias de submissão e rebeldia. São Paulo: Casa do Psicólogo, 1999.

PARANÁ. Secretaria do Estado de Educação. Resolução n. 1690, de 24 de abril de 2011. Institui a partir de 2011, em caráter permanente, o Programa de Atividades Complementares Curriculares em Contraturno na Educação Básica na Rede Estadual de Ensino. Curitiba, PR, 24 maio 2011a. Disponível em: <http://www. legislacao.pr.gov.br/legislacao/pesquisarAto.do?action=exibir\&codAto=69240\& indice=1\&totalRegistros=1 > . Acesso em: 20 maio 2013.

PARANÁ. Secretaria do Estado da Educação. Instrução n. 007/2011 - SUED/SEED. Assunto: critérios para a abertura da demanda de horas-aula, do suprimento e das atribuições dos profissionais das Salas de Apoio à Aprendizagem do Ensino Fundamental, da Rede Pública Estadual de Educação. 2011. Curitiba, 4 jul. 2011b. Disponível em: <http://www.educacao.pr.gov.br/arquivos/File/instrucoes/instrucao0072011.pdf >. Acesso em: 26 jun. 2012.

PARANÁ. Secretaria do Estado da Educação. Instrução n. 016/2011 - SEED/ SUED. Assunto: Estabelece critérios para o atendimento educacional especializado em SALA DE RECURSOS MULTIFUNCIONAL TIPO I, na Educação Básica área da deficiência intelectual, deficiência física neuromotora, transtornos globais do desenvolvimento e transtornos funcionais específicos. Curitiba, PR, 22 nov. 2011c. Disponível em: <http://www.educacao.pr.gov.br/arquivos/File/instrucoes/Instrucao162011.pdf >. Acesso em: 30 jul. 2013. 
PARANÁ. Secretaria do Estado de Educação. Instrução 020/2012 - SUED/SEED. Assunto: Matriz Curricular para os Ensino Fundamental, anos finais, e para o Ensino Médio, da Rede Pública de Educação Básica. Curitiba, PR, 12 dez. 2012. Disponível em: <http://www.educacao.pr.gov.br/arquivos/File/instrucoes\%20 2012\%20sued\%20seed/instrucao202012.pdf 〉. Acesso em: 2 jul. 2013.

PARO, V. H. Reprovação escolar: renúncia à educação. São Paulo: Xamã, 2001.

SOUZA, M. P. R. de. Medicalização na Educação Infantil e no Ensino Fundamental e as políticas de formação docente: retornando à patologia para justificar a não aprendizagem escolar - a medicalização e o diagnóstico de transtornos de aprendizagem em tempos de neoliberalismo. In: REUNIÃO ANUAL DA ANPED, 31., 2008, Caxambu. Anais... Caxambu: ANPEd, 2008. Disponível em: <http://31reuniao.anped.org.br/4sessao_especial/se\%20-\%2012\%20-\%20marilene\%20proena\%20rebello\%20de\%20souza\%20-\%20participante.pdf〉. Acesso em: 21 jul. 2013.

Recebido: 20/12/2014

Received: 12/20/2014

Aprovado: $15 / 04 / 2014$

Approved: 04/15/2014 
